\title{
Juçara (Euterpe edulis) pulp as a substrate for probiotic bacteria fermentation: Optimisation process and antioxidant activity
}

\author{
Karla Bigetti Guergoletto*, Carolina Saori Ishii Mauro, Sandra Garcia \\ Department of Food Science and Technology, State University of Londrina, Celso Garcia Cid Road, Km 380, C.P.:6001, 86051-970, \\ Londrina, Brazil
}

\section{A B S TR A C T}

\begin{abstract}
Juçara fruit (Euterpe edulis) has received considerable attention because of its high content of phenolic compounds. However, its suitability as a matrix for probiotic bacteria is not known yet. The objective of this study was to evaluate the $\mathrm{pH}$ and temperature conditions for the fermentation in juçara pulp by Lactobacillus reuteri and Lactobacillus plantarum. The optimised conditions were determined by central composite rotational design, and used for the analysis of cellular viability, sugar content, $\mathrm{pH}$, lactic acid, total phenolics and antioxidant activity during $80 \mathrm{~h}$ of fermentation. The conditions for probiotic growth were $32{ }^{\circ} \mathrm{C}$ with a pH of 5.7 for $L$. reuteri and $25{ }^{\circ} \mathrm{C}$ with a $\mathrm{pH}$ of 5.0 for L. plantarum, and $30 \mathrm{~h}$ of fermentation time for both bacteria. The viabilities remained above $8.6 \pm 0.2$ log colony forming units $(\mathrm{cfu}) / \mathrm{mL}$, and at $536.7 \mathrm{mg}$ gallic acid equivalent (GAE)/100 mL of total phenolic reached. L. reuteri consumed all of the glucose and fructose present in juçara, whereas L. plantarum used only glucose. After 28 days of refrigerated storage, the cell viability of probiotics remained at $8.7 \log \mathrm{CFU} / \mathrm{mL}$ with an increase in the antioxidant activity. Juçara pulp can be effective for a probiotic growth substrate and the production of new functional beverage.
\end{abstract}

Keywords: Probiotic; Experimental design; Juçara palm fruit; Total phenolics

\section{INTRODUCTION}

Juçara (Euterpe edulis) is one among the palms belongs to the family Arecaceae. Seven species are distributed in the tropics. In Brazil juçara is found mainly in the Atlantic forests (Borges et al., 2011).

Juçara is known for producing an excellent quality of palm heart with a high economic value. However, the plant has no regrowth mechanism, and palm heart extraction causes death of the plant. This palm tree also produces a round fruit with a glossy black thin pulp covering the seed, similar to the well-known açai berry (Euterpe oleracea) (De Brito et al., 2007). Moreover, because of its thin pulp, juçara fruit is often consumed in the form of juice, pulp and as an ingredient in many foods (Felzenszwalb et al., 2013).

Although the juçara tree is in danger of extinction due to illegal palm extraction, the use of its fruit in foods presents a potential economic, environmental, and nutritional alternative that could help preserve the species. The juçara fruit is rich in bioactive compounds with high antioxidant activity and has mineral elements, such as potassium, iron and zinc in amounts close to or higher than those found in açai (Borges et al., 2011). Recent studies have demonstrated that juçara pulp may exert high antioxidant effects in vitro (Borges et al., 2011; Vieira et al., 2013; Schulz et al., 2015), and its consumption can cause a positive effect on the antioxidant status and oxidative damage of healthy individuals (Cardoso et al., 2015). It is well-known that fruits and vegetables are important food sources due to their macro nutrients, vitamins, minerals, dietary fibre and antioxidants. However, they are a perishable commodity and not easily obtained depending on the season and region. For this reason, many technological resources can be employed to maintain or improve the safety, sensory properties and storage of fruits and vegetables. 
In the food industry, fermentation is the main way improve the sensory characteristics and to eliminate undesirable constituents and thereby enriching the nutritional properties (Jaiswal and Abu-Ghannam, 2013). Besides that, fermentation by probiotic bacteria could provide additional health benefits, since the regular consumption of probiotic microorganisms provides benefits, such as the stimulation of the immune system, inhibition of pathogens, regulation of intestinal function, reduction in serum cholesterol levels, improvement in inflammatory bowel disease, and suppression of Helicobacter pylori infection in the stomach (Nurmi et al., 1992, Hörmannsperger and Haller 2010, Remus et al., 2011).

Even though most probiotics are found in dairy-based products, new scientific data has addressed the effects of fermented vegetable products on health. This is due to the high levels of beneficial substances in fruits which, allied with the benefits of probiotics, can provide additional contributions to consumer health (Peres et al., 2012).

Although there are several studies showing the antioxidant potential of juçara fruit, there are no studies yet indicating its use as a suitable medium for probiotic bacteria fermentation. This way, this study aimed to optimise the parameters of $\mathrm{pH}$ and temperature during the fermentation process by L. reuteri LR92 and L. plantarum BG 112 in juçara pulp, using a central composite rotational design (CCRD), and bacterial growth as the response function. Under optimised conditions, the fermentation parameters were determined over the course of $80 \mathrm{~h}$. In addition, we also investigated the influence of the fermentation process on the antioxidant activity and the stability during a refrigerated $\left(4^{\circ} \mathrm{C}\right)$ storage period of 28 days, to evaluate the potential use of juçara pulp as a cultivation media for probiotics strains of Lactobacillus for further use as a new non-dairy probiotic product.

\section{MATERIALS AND METHODS}

\section{Juçara pulp}

Juçara fruits were kindly provided by Bimini Farm (Rolândia, Paraná, Brazil) and was from the 2012 harvest of Euterpe edulis palm trees.

The product used in the present study was the juçara pulp, which was obtained by the following procedure: the fruits were washed with clean water and sanitised for 30 minutes in water containing chlorine at a concentration of $200 \mathrm{mg} / \mathrm{kg}$. The fruits were then rinsed with clean water, and pulp was prepared by adding water to the fruit in a ratio of 2:1 (w/v) and pulped using a homogeniser for 1 minute at low frequency to preserve seed viability. The seeds were separated for planting and the pulp was frozen in $250 \mathrm{~mL}$ portions.

Immediately prior to use, the frozen pulps were thawed under refrigeration for 18 hours and filtered, first through fabric to remove the sludge, and then with a qualitative filter paper (0.5 mm, Synth, Diadema, Brazil) using a Büchner funnel under vacuum. Thereafter, the $\mathrm{pH}$ of the pulp was adjusted using $3 \mathrm{~N} \mathrm{NaOH}$ (Sigma-Aldrich, São Paulo, Brazil) or 10\% acetic acid (Sigma-Aldrich, São Paulo, Brazil) according to the central composite rotational experimental design, followed by pasteurization at $80^{\circ} \mathrm{C}$ in a water bath for 1 minute, and then cooled in an ice bath.

\section{Juçara pulp chemical composition}

The chemical composition of the resultant juçara pulp was characterised by determining the following: moisture content was measured in a laboratory oven at $105^{\circ} \mathrm{C}$, protein by the Kjeldahl method, ash in a muffle at $550^{\circ} \mathrm{C}$, and total fibre by the Enzymatic-Gravimetric Method (AOAC, 2005). The $\mathrm{pH}$ was measured using a $\mathrm{pH}$ meter (potentiometer - Ion PH300), and the soluble solids with a portable refractometer (Atago refractometer pocket, Japan). Total sugar content was analysed by phenol sulfuric acid method (Dubois, 1956) using as glucose as standard, and lipid according to the method of Bligh and Dyer (1959). In determining the mineral content, the pulp samples were first digested with a mixture of nitric and perchloric acids in the ratio $2: 1(\mathrm{v} / \mathrm{v})$, then diluted with $50 \mathrm{~mL}$ deionised water and the elements determined according to Silva (2009).

\section{Microorganisms and pre inoculum preparation}

The probiotic strains of Lactobacillus reuteri LR92 (DSM 26866) and L. plantarum BG112 (LMG 23520) were provided by Clerici Sacco (Italy). Each cultures powders were diluted at concentration of $0.01 \%(\mathrm{w} / \mathrm{v})$ in pasteurised juçara pulp and the mixture was kept frozen with 20\% (v/v) sterile glycerol (Synth, Diadema, Brazil). Prior to testing, pre-inoculums were obtained from two activations of $1 \%$ (v/v) on juçara pulp and incubation at $37^{\circ} \mathrm{C}$ for 18 hours.

\section{Optimisation of $L$. reuteri or $L$. plantarum growth in juçara pulp}

The optimum fermentation conditions (initial $\mathrm{pH}$ and incubation temperature) for both microorganisms were determined using the response surface methodology in a central composite rotational experimental design (CCRD) consisting of a $2^{2}$ factorial [with two levels (-1 and 1) and two factors, $\mathrm{x} 1$ (initial $\mathrm{pH}$ ) and $\mathrm{x} 2$ (incubation temperature, $\left.{ }^{\circ} \mathrm{C}\right)$, including four axial and three central points, totalling eleven randomly performed trials.

The fermentation parameters applied to the CCRD were established by preliminary tests and based on the range that 
the Lactobacillus spp. can grow (Pereira and others 2011). In this manner, the initial $\mathrm{pH}$ for $L$. reuteri was from 3.6 to 6.4, and for L. plantarum from 5.0 to 7.9. The temperature ranged from $10.8 \pm 1{ }^{\circ} \mathrm{C}$ to $39 \pm 1{ }^{\circ} \mathrm{C}$ for both bacteria.

For each experimental run with each microorganism, one percent of a pre-inoculum (containing approximately $10^{8} \mathrm{CFU} / \mathrm{mL}$ ) was added to screw-cap glass vials containing $100 \mathrm{~mL}$ of pasteurised juçara pulp to an initial count of $10^{6} \mathrm{CFU} / \mathrm{mL}$. This concentration was chosen based on the preliminary tests, in which concentrations of 1.0, 5.5 and $10.0 \%$ did not presented differences on cell viability for both lactobacilli. Moreover, using the lowest pre-inoculum concentration allows economising in product development. Besides, this concentration meets the recommendation for probiotic foods: minimal counts of $6.00 \log \mathrm{CFU} / \mathrm{mL}$ for better efficacy in regulating beneficial effects. This mixture was incubated for 48 hours at different temperatures, according to the experimental design. The number of viable cells was determined at the end of the incubation period using Man-Rogosa-Sharp (MRS) agar (Himedia, Mumbai, India) and response variables were recorded as functions of $\log \mathrm{CFU} / \mathrm{mL}$.

A second order response surface model was used to fit the experimental data using equation 1 :

$\mathrm{Y}=\beta_{0}+\beta_{1} \mathrm{x}_{1}+\beta_{2} \mathrm{x}_{2}+\beta_{11} \mathrm{x}_{1}^{2}+\beta_{22} \mathrm{x}_{2}^{2}+\beta_{12} \mathrm{x}_{1} \mathrm{x}_{2}$

Where $\mathrm{Y}=$ response function, $\mathrm{x}_{1}$ and $\mathrm{x}_{2}=$ coded independent variables, and $\beta=$ estimated regression coefficients.

The regression and variance analysis (ANOVA) was performed using the software Statistica 7.0 (StatSoft Inc., Tulsa, USA) to estimate and test the significance $(\phi \leq 0.05)$ of the parameters for the mathematical models. The response surface plots were constructed from the adjusted models, and the desirability of the predicted values was evaluated.

\section{Lactobacilli growth and fermentation process}

A lactobacilli growth study was conducted under optimal fermentation conditions, designed using the response surface methodology $\left(\mathrm{pH} 5.7\right.$ and $32{ }^{\circ} \mathrm{C}$ for L. reuteri, and $\mathrm{pH} 5.0$ and $25^{\circ} \mathrm{C}$ for L. plantarum) with the aim of eliciting the appropriate fermentation time and the sugar consumption for the juçara pulp matrix. In addition, analysis for the total phenolic content and antioxidant activity were also conducted to verify the influence of fermentation parameters on juçara antioxidant activity.

\section{Storage stability}

The juçara pulp (150 mL in glass bottles) was fermented for 30 hours under the optimised conditions as determined by the growth study. After fermentation, the samples were stored in a cold room at $4{ }^{\circ} \mathrm{C}$ for 28 days. Analysis of viable cell counts, total phenolic and antioxidant activity during storage were determined every 7 days in triplicate to calculate the average between 3 repetitions.

\section{Viable cell count determination}

The cellular viability was determined using the pour plate method. Fermented juçara pulp dilutions (1:9) were made with sterile peptone-water $0.1 \%(\mathrm{w} / \mathrm{v})$, followed by plating on MRS agar (Himedia - Mumbai, India) and incubation at $37^{\circ} \mathrm{C}$ in anaerobic jars for 48 hours.

\section{$\mathrm{pH}$, sugars and lactic acid determinations}

The $\mathrm{pH}$ values of the samples during the growth study were determined through direct measurements in a Ion PH300 potentiometer at $25^{\circ} \mathrm{C}$.

For the determination of sugars and lactic acid, the cultures were first centrifuged at $10,000 \mathrm{x} g$ for 10 minutes and the supernatant filtered using a Millex-GV, PVDF hydrophilic membrane $(0.22 \mu \mathrm{m}$ pore size; Millipore, Billerica, MA, USA).

The sugars (glucose, fructose, galactose and rhamnose) were analysed using high performance anion exchange chromatography (HPAEC). This method has been used for a mixture of sugars, because of benefits like high sensitivity, simplicity, organic solvent freedom and no need doe derivatisation (Cai et al., 2005, Guan et al., 2012). Aliquots $(10 \mu \mathrm{L})$ of the filtrate (PVDF membrane, $0.22 \mu \mathrm{m}$, Millipore, Billerica, MA, USA) were automatically injected into the Ion Chromatography System (ICS5000, Dionex Canada Ltd., Oakville, Canada), coupled with pulsed amperometric detection (PAD, cell with disposable working gold electrode and $\mathrm{pH}-\mathrm{Ag} / \mathrm{AgCl}$ reference electrode, Dionex/Thermo Scientific) and equipped with a gradient pump (Model SP-5). The carbohydrates were separated using a CarboPac ${ }^{\mathbb{B}}$ PA1 analytical column $[250 \mathrm{~mm} \times 4 \mathrm{~mm}$, $10 \mu \mathrm{m}$ particle size, polystyrene/divinylbenzene ( $2 \%$ crosslinked) substrate agglomerated with quaternary ammonium functionalised latex (5\% cross-linked), DionexCarboPac ${ }^{\circledR}$ ], but preceded by passage through a CarboPac ${ }^{\circledR}$ PA1 guard column $(50 \mathrm{~mm} \times 4 \mathrm{~mm})$. The chromatographic runs were performed at a flow rate of $1.0 \mathrm{~mL} / \mathrm{min}$ at $30^{\circ} \mathrm{C}$ with gradient elution using ultra-pure water (resistivity of 18.2 $\mathrm{M} \Omega \mathrm{cm}$, solvent A) and $0.25 \mathrm{~mol} / \mathrm{L} \mathrm{NaOH}$ (solvent B). Furthermore, the column was washed for 10 min after each injection using $0.2 \mathrm{~mol} / \mathrm{L} \mathrm{NaOH}$, and the eluent ratio was returned to the initial conditions after 33 minutes, with a total run time of 47 minutes. The polypropylene bottles containing mobile phases were continuously pressurised with nitrogen gas to minimise contamination by carbonate. A quadruple potential waveform was applied $(\mathrm{E}=$ potential, 
$\mathrm{t}=$ duration) using the following settings: $\mathrm{E}_{1}=+0.1 \mathrm{~V}, \mathrm{t}_{1}$ $=400 \mathrm{~ms} ; \mathrm{E}_{2}=-2.0 \mathrm{~V}, \mathrm{t}_{2}=20 \mathrm{~ms} ; \mathrm{E}_{3}=+0.6, \mathrm{t}_{3}=10 \mathrm{~ms}$; and $\mathrm{E}_{4}=-0.10, \mathrm{t}_{4}=70 \mathrm{~ms}$. Integration occurred from 200 $\mathrm{ms}$ to $400 \mathrm{~ms}$ during the $\mathrm{E}_{1}$ application.

Carbohydrate standards of glucose, fructose, rhamnose and galactose (all provided from Sigma, Brazil) were used to identify the different sugars on the basis of their retention times and for external calibration solutions. Chromatogram analysis was carried out using Chromeleon software version 6.8 (Dionex Corporation). The carbohydrate concentrations were expressed as the mean \pm standard deviation in grams of glucose, fructose, galactose or rhamnose per litre of sample.

Lactic acid production was monitored via High Performance Liquid Chromatography (HPLC-Shimadzu) equipped with a C18 column $5 \mu \mathrm{m}$ ODS 1 (4.6 mm x $250 \mathrm{~mm}$ ) (Waters Spherisorb, Ireland) and a UV detector operating at $210 \mathrm{~nm}$. Elution was conducted at $20^{\circ} \mathrm{C}$ with a flow rate of $0.2 \mathrm{~mL} / \mathrm{min}$ using $\mathrm{H}_{2} \mathrm{SO}_{4} 2 \mathrm{mM}$ ) as the mobile phase.

\section{Total Phenolics analysis}

The total phenolic content was analysed according to the Folin-Ciocalteu method (Fang and Bhandari, 2011) using gallic acid as the standard.

\section{Determination of antioxidant activity}

The free radical 2,2 Diphenyl-1-picrylhydrazyl (DPPH) and the cation radical [2.2' azinobis (3-ethylbenzthiazoline sulfonic acid-6)] (ABTS ${ }^{+}$) methods were used to determine free radical scavenging potential of each sample.

The DPPH was performed according to Brand-Williams and others (1995) with modifications. Aliquots of $0.05 \mathrm{~mL}$ of each juçara pulp were added to $1 \mathrm{~mL}$ of acetate buffer (pH 5.5), $1 \mathrm{~mL}$ of absolute ethanol and $0.5 \mathrm{~mL}$ of DPPH (Sigma-Aldrich, Brazil) solution (0.25 mM). The reaction mixture was left in the dark for 30 minutes $25^{\circ} \mathrm{C}$ followed by measuring the absorbance at $517 \mathrm{~nm}$. The quantification was calculated using a Trolox (6-hydroxy2,5,7-tetramethylchroman-2-carboxylic acid) (SigmaAldrich, Brazil) calibration curve $\left(0.5 \cdot 10^{-4}\right.$ to $\left.0.02 \mathrm{mM}\right)$ and the results expressed in micromole Trolox per millilitre of sample.

The cation radical, ABTS.+, was prepared from ABTS [2.2' azinobis (3-ethylbenzthiazoline sulfonic acid-6) (Sigma-Aldrich, Brazil), according to Sanches-Gonzales et al., (2005) with modifications. Before analysis, the ABTS $^{+}$(7 mM to $2.45 \mathrm{mM}$ potassium persulfate) solution was prepared in the dark for 16 hours. Upon analysis, the solution was diluted with sodium phosphate buffer $(\mathrm{pH}$ 7.4) to provide a solution of absorbance of $0.7 \pm$
0.02 at $730 \mathrm{~nm}$. The analysis took place by adding $30 \mathrm{uL}$ of sample and $6 \mathrm{~mL}$ of the diluted solution of $\mathrm{ABTS}^{+}$, and after 6 minutes of reaction, the absorbance was read at $730 \mathrm{~nm}$. The quantification was based on a standard curve of Trolox (2.5 to $20 \mathrm{mM}$ ) and the results were expressed in micromole Trolox per millilitre of sample.

\section{RESULTS AND DISCUSSION}

\section{Chemical and mineral composition of the juçara pulp}

The chemical composition of the juçara pulp used as fermentation substrate by probiotic lactobacilli is shown in Table 1. The protein and lipid contents of the extract were lower than those obtained by Borges et al. (2011), who observed a variation of 5.13 to $8.21 \%$ dry basis (db) protein and 18.45 to $44.05 \%$ (db) lipids in different cultivars of juçara analysed. Regarding the mineral composition, higher amounts of potassium were found in the extract in relation to the other minerals, followed by calcium, magnesium and phosphorus. The levels of iron in the present study were similar to those reported by Garbin (2011), (1.39 mg/100 g). However, the results of our study were higher for the other minerals (Ca: $16.88 \mathrm{mg} / 100 \mathrm{~g}, \mathrm{Mg}: 5.25 \mathrm{mg} / 100 \mathrm{~g}$, Mn: 0:26 mg/100 g, Zn: 0:25 mg/100 g and K: $5.51 \mathrm{mg} / 100 \mathrm{~g})$.

Previous studies demonstrated that similarly to other types of fruits, factors such as geographical location of growth and harvest can significantly affect the chemical composition of juçara fruits (Borges et al., 2011) which justify the differences between the studies. Besides, the chemical composition showing high content of nutrients such as sugars and minerals, juçara pulp can become a promising nutrient for probiotic bacteria growth making a healthy product for human consumption (Ding, Shah, 2008).

\section{Optimisation of $L$. reuteri and $L$. plantarum growth in juçara pulp}

Since probiotic bacteria are found mainly in dairy products, it is important to study and determine the best conditions for fermentation in fruits and vegetables. For this reason, an experimental design was carried out to evaluate the effect of initial $\mathrm{pH}$ and fermentation temperature on $L$. reuteri and L. plantarum growth on juçara pulp. The results are presented in Table 2. According to the results, there are different behaviours between the two microorganisms under the different conditions tested. Temperatures below $15^{\circ} \mathrm{C}$ were not favourable for the growth of L. renteri, and a small increase in growth was observed for $L$. plantarum when extreme temperatures (10.8 and $39^{\circ} \mathrm{C}$ ) were used. This behaviour demonstrated the mesophilic characteristics of the studied strains as low and high temperatures were not favourable for growth of both bacterial species. 
Table 1: Chemical and mineral ( $\mathrm{db}$ ) composition of juçara pulp used for fermentation

\begin{tabular}{lccc}
\hline Chemical & Mean value \pm Standard deviation & Mineral $^{*}$ & Mean value \pm Standard deviation \\
\hline Moisture (\%) & $97.11 .( \pm 0.10)$ & $\mathrm{P}$ & $11.2( \pm 1.10)$ \\
Protein (\%) & $0.089 .( \pm 0.04)$ & $\mathrm{K}$ & $191.3( \pm 14.0)$ \\
Lipids (\%) & $0.08 .( \pm 0.02)$ & $\mathrm{Mg}$ & $13.0( \pm 0.30)$ \\
Soluble solids (Brix) & $4.30 .( \pm 0.20)$ & $\mathrm{Ca}$ & $35.4( \pm 7.00)$ \\
Ash (\%) & $0.002 .( \pm 0.00)$ & $\mathrm{Mn}$ & $0.9( \pm 0.07)$ \\
pH & $4.90 .( \pm 0.10)$ & $\mathrm{Fe}$ & $1.2( \pm 0.60)$ \\
Sugars (\%) & $2.80 .( \pm 0.25)$ & $\mathrm{Zn}$ & $0.45( \pm 0.01)$ \\
Total fibres (\%) & ND & & \\
\hline
\end{tabular}

ND: Not detected, * Results expressed as $\mathrm{mg} / 100 \mathrm{~g}, \mathrm{db}=$ dry basis

\begin{tabular}{|c|c|c|c|c|c|}
\hline Assay & Initial pH LR & Initial pH LP & Fermentation temperature $\left({ }^{\circ} \mathrm{C}\right)$ & $\log$ CFU/mL LR & $\log$ CFU/mL LP \\
\hline 1 & $4.0(-1)$ & $5.5(-1)$ & $15 \pm 0.5(-1)$ & $7.20 \pm 0.12$ & $8.45 \pm 0.02$ \\
\hline 2 & $4.0(-1)$ & $5.5(-1)$ & $35 \pm 0.5(+1)$ & $8.54 \pm 0.06$ & $8.63 \pm 0.18$ \\
\hline 3 & $6.0(+1)$ & $7.5(+1)$ & $15 \pm 0.5(-1)$ & $8.69 \pm 0.36$ & $8.59 \pm 0.33$ \\
\hline 4 & $6.0(+1)$ & $7.5(+1)$ & $35 \pm 0.5(+1)$ & $8.70 \pm 0.50$ & $8.10 \pm 0.02$ \\
\hline 5 & $3.6(-1.41)$ & $5.0(-1.41)$ & $25 \pm 0.5(0)$ & $7.49 \pm 0.09$ & $8.81 \pm 0.10$ \\
\hline 6 & $6.4(+1.41)$ & $7.9(+1.41)$ & $25 \pm 0.5(0)$ & $8.83 \pm 0.23$ & $9.04 \pm 0.12$ \\
\hline 7 & $5.0(0)$ & $6.5(0)$ & $10.8 \pm 0.5(-1.41)$ & $6.78 \pm 0.02$ & $7.26 \pm 0.04$ \\
\hline 8 & $5.0(0)$ & $6.5(0)$ & $39.0 \pm 0.5(+1.41)$ & $8.78 \pm 0.10$ & $7.72 \pm 0.05$ \\
\hline 9 & $5.0(0)$ & $6.5(0)$ & $25 \pm 0.5(0)$ & $8.93 \pm 0.05$ & $8.81 \pm 0.04$ \\
\hline 10 & $5.0(0)$ & $6.5(0)$ & $25 \pm 0.5(0)$ & $8.90 \pm 0.10$ & $8.83 \pm 0.03$ \\
\hline 11 & $5.0(0)$ & $6.5(0)$ & $25 \pm 0.5(0)$ & $8.91 \pm 0.07$ & $8.83 \pm 0.05$ \\
\hline
\end{tabular}

Estimated effects of the independent variables $(\mathrm{x} 1=\mathrm{pH}$ and $\mathrm{x} 2=$ incubation temperature $)$ on the response $(\mathrm{Y}=\log$ $\mathrm{CFU} / \mathrm{mL}$ ) were also analysed, and according to these results, growth of $L$. reuteri was significantly influenced $(p<0.05)$ by the initial $\mathrm{pH}$ and incubation temperature. Both quadratic effects were negative, indicating the presence of maximum bacterial growth. For L. plantarum, only the quadratic term of incubation temperature (x2 variable) had a significant effect $(p=0.002)$ on cell viability, the region of greatest response.

The results shown in Table 2 were subjected to analysis of variance (ANOVA) and adjusted to a quadratic model, from which the equations $\mathbf{2}$ and $\mathbf{3}$ were obtained for the cell growth of $L$. reuteri and $L$. plantarum, respectively.

Viability $(\log \mathrm{CFU} / \mathrm{mL})=8.91+0.44 \mathrm{pH}-0.30 \mathrm{pH}^{2}+$ $0.52 \mathrm{~T}-0.49 \mathrm{~T}^{2}-0.33 \mathrm{pHx} \mathrm{T}$

Viability $(\log \mathrm{CFU} / \mathrm{mL})=8.82+0.109 \mathrm{pH}^{2}-0.61 \mathrm{~T}^{2}-$ $0.17 \mathrm{pHxT}$

Where, $\mathrm{T}=$ temperature $\left({ }^{\circ} \mathrm{C}\right)$ and $\mathrm{pH}=\mathrm{pH}$ value.

The model obtained for $L$. reuteri growth was significant at the $95 \%$ confidence level, as the calculated value $\mathrm{F}$ (12.68) was higher than the tabulated value F (5:05). The determination coefficient for the regression was 0.92 , indicating that the model could be used as a predictor and was therefore used to generate the response surface curve (Fig. 1a). Similarly, the model obtained for L. plantarum was statistically significant at the $95 \%$ confidence level, and again, the calculated value of $F$ (11:56) was higher than the tabulated value $\mathrm{F}(4: 53)$. The percentage of variance explained by this model was $89 \%$. The response surface was plotted and is shown in Fig. 1 b.

It was verified that an increase in $L$. reuteri growth occurred at a temperature of $15^{\circ} \mathrm{C}$ when the $\mathrm{pH}$ value ranged from 4.0 to 6.0 (Fig. 1a). Similarly, increasing the temperature increased the cell viability, reaching a maximum value in the range of $\mathrm{pH} 5.0$ to 6.4 and temperatures between 25 and $35{ }^{\circ} \mathrm{C}$. The optimal conditions for $L$. reuteri growth in juçara pulp were calculated based on the binomial $\mathrm{pH}$ $\mathrm{x} \mathrm{T}$, resulting in an initial $\mathrm{pH}$ of 5.7 and a fermentation temperature of $32{ }^{\circ} \mathrm{C}$.

For the growth of L. plantarum (Fig. 1b), the $\mathrm{pH}(\mathrm{x} 1)$ variation in the range studied exerted little influence on viability. However, the variable $\mathrm{x} 2$ (incubation temperature) resulted in lower probiotic growth at higher (above $35^{\circ} \mathrm{C}$ ) or lower (below $15^{\circ} \mathrm{C}$ ) values than within the range of $20{ }^{\circ} \mathrm{C}$ and $30{ }^{\circ} \mathrm{C}$. Best growth was observed at $25^{\circ} \mathrm{C}$ and at $\mathrm{pH}$ values of 5.0 and 7.9. As the $\mathrm{pH}$ of the juçara pulp in natura was approximately 4.9 , choosing an initial $\mathrm{pH}$ of 5.0 is more desirable than 7.9 because it may result in reduced costs associated with pulp neutralisation, as well as preventing operational risks with material contamination. 


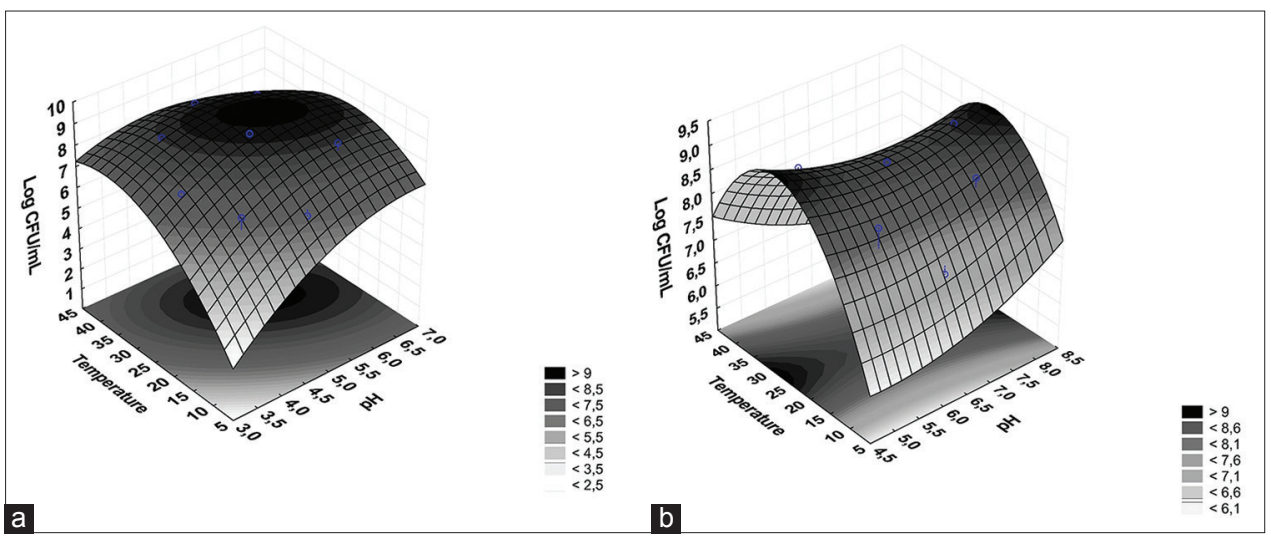

Fig 1. 3-D surface plots of (a) L. reuteri, and (b) L. plantarum. Cell viability (log CFU/mL) in juçara pulp as a function of initial $\mathrm{pH}$ and temperature $\left({ }^{\circ} \mathrm{C}\right)$.

The results observed for the growth of $L$. reuteri and L. plantarum in juçara pulp were similar from those found in studies with other vegetables (Jaiswal et al., 2012). Yoon et al., (2006), while studying the fermentation of sterilised cabbage juice by L. plantarum, L. casei and L. delbrueckii, reported a growth of $\sim 8.00 \log \mathrm{CFU} / \mathrm{mL}$ within 48 hours of fermentation at $30^{\circ} \mathrm{C}$. Pereira et al., (2011), while fermenting cashew apple juice with $L$. casei, found optimised values of $\mathrm{pH} 6.4$ and $30{ }^{\circ} \mathrm{C}$ fermentation temperature. Costa et al., (2013) obtained optimised fermentation conditions with $L$. casei for sonicated pineapple juice with a $\mathrm{pH}$ of 5.8 and an incubation temperature of $31^{\circ} \mathrm{C}$. In the latter two studies, a slight variation was observed in conditions that resulted in higher biomass and viability. According to Pereira et al., (2011), the effect of initial $\mathrm{pH}$ and growth temperature depends on the substrate and the lactobacilli strains studied. Therefore, the use of an optimisation procedure such as the response surface methodology is an important tool when studying new plant matrices for the growth of probiotic bacteria.

\section{Fermentation process}

The optimum conditions for the growth of $L$. renteri $\left(\mathrm{pH} 5.7\right.$ and incubation temperature at $32{ }^{\circ} \mathrm{C}$ ) and L. plantarum (pH 5.0 and incubation temperature at $25^{\circ} \mathrm{C}$ ) in juçara pulp obtained from the optimisation experiments were used to evaluate the growth profile and fermentation time. Fig. 2 represents bacterial viability, $\mathrm{pH}$ and sugar consumption during fermentation of juçara pulp for 72 hours. It was observed that both $L$. reuteri (Fig. 2a) and L. plantarum (Fig. 2b) required a similar fermentation time to achieve the same cell count numbers, between 24 and 32 hours, reaching a maximum growth in the juçara pulp, with a viable count number of $8.8 \pm 0.2 \log \mathrm{CFU} / \mathrm{mL}$ and $8.6 \pm 0.2 \log \mathrm{CFU} / \mathrm{mL}$, respectively. Similar cell counts were observed by Moreira et al. (2017), which obtained a survival of $8.33 \log \mathrm{CFU} / \mathrm{mL}$ when evaluating a beverage containing a mixture of mango and juçara pulp with added Lactobacillus rhamnosus GG.
The present results are also interesting for commercial scale production, since in market products it is possible to find viable counts starting from $7 \log \mathrm{CFU} / \mathrm{mL}$ depending on the product matrix and probiotic strain. For example, the American Company, Tropicana, produces beverages containing a mixture of natural juices with the addition of Bifidobacterium lactics presenting a count of $9 \log \mathrm{CFU} /$ portion, while the Perkii Company produces flavoured waters with $L$. casei (Lc431) at a concentration of $7 \log$ CFU/portion (Wyvill, 2012).

Since cell viability is the main factor to be considered in functional probiotic products when stopping the fermentation at 30 hours. Apart from obtaining the highest number of viable cells, lower $\mathrm{pH}$ values are achieved from the formation of acids during fermentation, which increases safety during storage and prevents the development and colonising of pathogenic bacteria (Costa et al., 2013).

The $\mathrm{pH}$ decrease caused by lactic acid production occurred from the consumption of sugars present in the juçara pulp during Lactobacillus growth (Fig. 2c, d and e). These results are in agreement with other studies (Yoon et al., 2006, Di Cagno et al., 2011, Costa et al., 2013), suggesting that different vegetables such as tomato, cashew, cabbage, and banana can serve as adequate growth substrates for lactic acid bacteria, resulting in higher numbers during lactic acid production.

The major sugars present in the unfermented pulp were glucose $(1.7 \pm 0.1 \mathrm{~g} / \mathrm{L})$, fructose $(1.1 \pm 0.1 \mathrm{~g} / \mathrm{L})$ and trace amounts of galactose $(0.015 \pm 0.001 \mathrm{~g} / \mathrm{L})$. Both microorganisms preferentially used glucose for growth and lactic acid production. However, rapid consumption of glucose by $L$. reuteri occurred, and after 16 hours only trace amounts of glucose were detectable. After 40 hours of fermentation nearly all fructose present in the nutrient medium was consumed by $L$. renteri. By contrast, the pulp fermented by $L$. plantarum showed a gradual decrease in glucose consumption rate, with total consumption achieved 


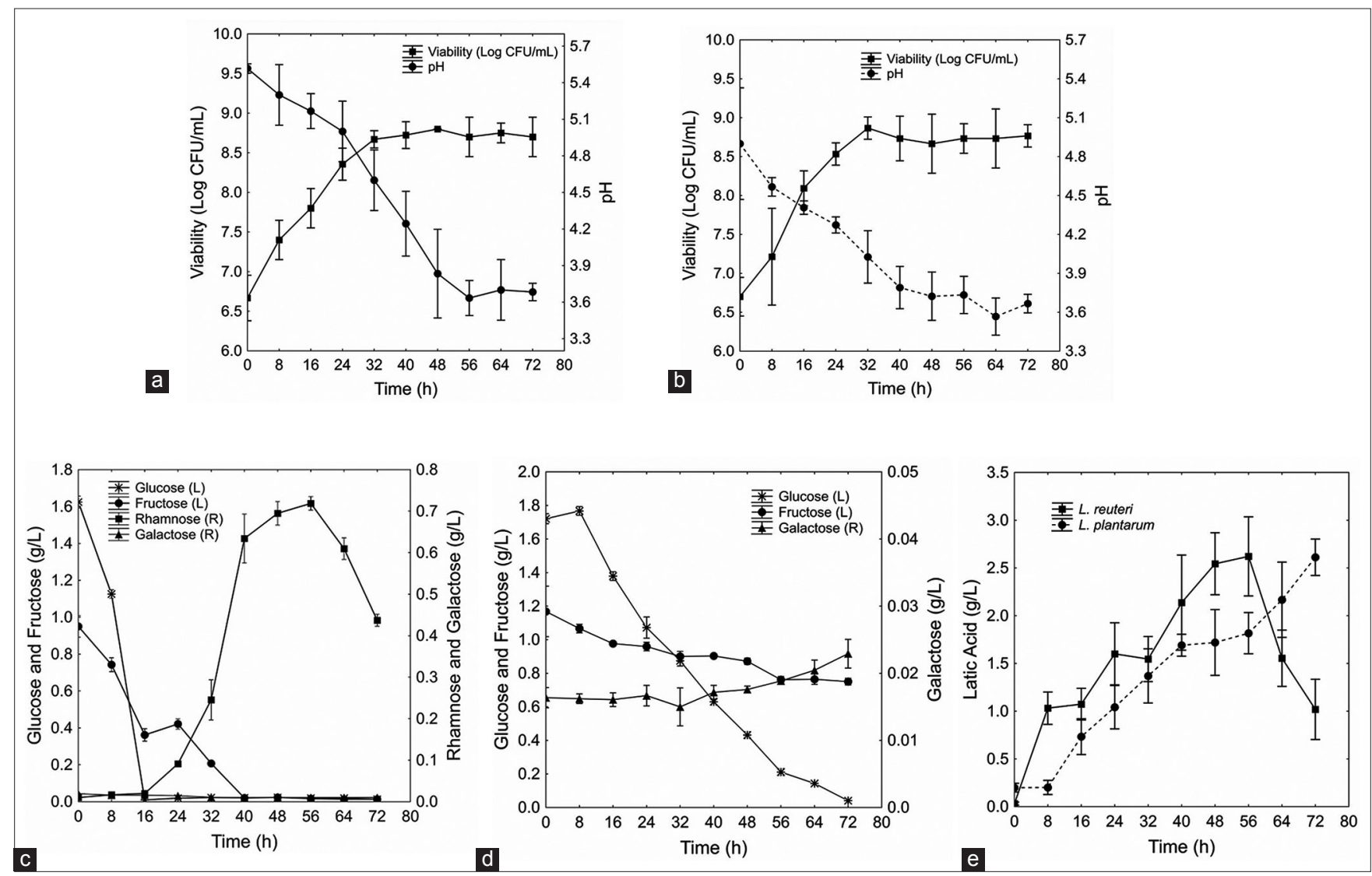

Fig 2. $\mathrm{pH}$ values and cell viability $(\log \mathrm{CFU} / \mathrm{mL}$ ) of $L$. reuteri (a) and $L$. plantarum; individual sugar consumption by $L$. reuteri (c) and $L$. plantarum (d); and lactic acid production (e) during $72 \mathrm{~h}$ fermentation of juçara pulp.

after 72 hours of fermentation. A small amount of fructose was fermented by L. plantarum during the study period.

The differences in sugar consumption with different fermentation times may also have caused differences in lactic acid production; $L$. reuteri reached the highest concentration after 48 hours of fermentation, while L. plantarum took 72 hours to achieve the same lactic acid concentration (Fig. 2e).

After 16 hours of fermentation with L. reuteri, the appearance of rhamnose was observed in the growth medium, which increased during the fermentation period, peaking at 56 hours (Fig. 2a). From 64 hours, a decrease in rhamnose concentration was observed, which may have been caused by the consumption of this sugar by the bacteria, since the other carbohydrate sources had already become exhausted during this period. The rhamnose present after 16 hours of fermentation may have originated from the hydrolysis of cyanidin-3-rhamnoside. According to De Brito et al. (2007), this anthocyanin is found at a concentration of $7 \mathrm{mg} / 100 \mathrm{~g}(\mathrm{db})$ in juçara (E. edulis), and some types of Lactic Acid Bacteria, such as Lactobacillus (including L. reuteri), Streptococcus, Enterococcus, and Weissella; which possessed $\beta$-glucosidase activity (Otieno et al., 2005,
Hayek, 2013) directly acting on the anthocyanin, forming aglycones with higher antioxidant capacities compared to the glycosylated forms (Spagna et al., 2000).

Carbohydrate and organic acid metabolism by Lactobacillus sp. also varies with species and depends on the substrate and fermentation time (Hou et al., 2000, Wang et al., 2003). Mousavi et al. (2011), evaluating the fermentation of pomegranate using the probiotics, L. plantarum, $L$. delbrueckii and $L$. paracasei, found that all of these species were able to grow and metabolise glucose and fructose, however, the consumption rate was different between the species.

\section{Total phenolic and antioxidant activity during fermentation}

In the present study, methods measuring radical scavenging ability of DPPH and $\mathrm{ABTS}^{+}$were used to estimate the antioxidant activity of fermented juçara pulp stored for various periods and the results are shown in Table 3. According to Roginski and Lissi (2005), the use of more than one assay is often appropriate to estimate antioxidant activity as each method has its limitations.

Based on the results, fermentation with both microorganisms showed a significant increase in total 
Table 3: Total phenolic compounds and antioxidant activity of juçara pulp fermented by Lactobacillus plantarum and Lactobacillus reuteri for 72 hours

\begin{tabular}{lcccccc}
\hline $\begin{array}{l}\text { Time } \\
\text { (hours) }\end{array}$ & $\begin{array}{c}\text { Total phenolic } \\
\text { compounds } \\
(\mathbf{m g}\end{array}$ & $\begin{array}{c}\text { L. plantarum } \\
\text { DPPH. } \\
\text { GAE/100mL) }\end{array}$ & $\begin{array}{c}\text { ABTS.+ } \\
\text { Trolox/100mL) } \\
(\mu \mathrm{g} \text { Trolox/100mL) }\end{array}$ & $\begin{array}{c}\text { Total phenolic } \\
\text { compounds } \\
(\mathbf{m g ~ G A E} / 100 \mathrm{~mL})\end{array}$ & $\begin{array}{c}\text { L. reuteri } \\
\text { DPPH. } \\
(\mu \mathrm{g} \text { Trolox/100mL) }\end{array}$ & $\begin{array}{c}\text { ABTS.+ } \\
(\mu \mathrm{g} \text { Trolox/100mL) }\end{array}$ \\
\hline 0 & $447.3 \pm 2.00^{\mathrm{a}}$ & $136.4 \pm 10.61^{\mathrm{a}}$ & $54.4 \pm 3.53^{\mathrm{a}}$ & $473.7 \pm 0.67^{\mathrm{a}}$ & $138.3 \pm 5.43^{\mathrm{a}}$ & $61.9 \pm 10.84^{\mathrm{a}}$ \\
16 & $454.6 \pm 2.71^{\mathrm{a}}$ & $133.6 \pm 5.74^{\mathrm{a}}$ & $59.9 \pm 1.88^{\mathrm{a}}$ & $489.3 \pm 5.35^{\mathrm{a}}$ & $160.2 \pm 0.88^{\mathrm{b}}$ & $63.6 \pm 5.43^{\mathrm{a}}$ \\
24 & $514.43 \pm 7.36^{\mathrm{b}}$ & $156.4 \pm 7.98^{\mathrm{a}}$ & $60.1 \pm 0.23^{\mathrm{a}}$ & $482.7 \pm 16.06^{\mathrm{a}}$ & $165.2 \pm 10.61^{\mathrm{b}}$ & $67.4 \pm 2.12^{\mathrm{a}}$ \\
32 & $536.7 \pm 4.01^{\mathrm{bc}}$ & $133.3 \pm 2.56^{\mathrm{a}}$ & $59.2 \pm 0.47^{\mathrm{a}}$ & $537.14 \pm 5.35^{\mathrm{b}}$ & $160.8 \pm 3.68^{\mathrm{b}}$ & $76.9 \pm 0.47^{\mathrm{a}}$ \\
48 & $554.64 \pm 5.35^{\mathrm{c}}$ & $134.9 \pm 2.21^{\mathrm{a}}$ & $60.7 \pm 0.23^{\mathrm{a}}$ & $538 \pm 6.02^{\mathrm{b}}$ & $161.4 \pm 1.77^{\mathrm{b}}$ & $119.1 \pm 5.89^{\mathrm{b}}$ \\
64 & $565.52 \pm 16.7^{\mathrm{c}}$ & $142.1 \pm 13.25^{\mathrm{b}}$ & $60.1 \pm 0.54^{\mathrm{a}}$ & $531.9 \pm 13,50^{\mathrm{b}}$ & $156.8 \pm 11.05^{\mathrm{b}}$ & $120.7 \pm 2.12^{\mathrm{b}}$ \\
72 & $560.32 \pm 12.1^{\mathrm{c}}$ & $147.1 \pm 10.89^{\mathrm{b}}$ & $58.9 \pm 8.32^{\mathrm{a}}$ & $534.1 \pm 20,84^{\mathrm{b}}$ & $155.7 \pm 9.12^{\mathrm{b}}$ & $118.2 \pm 4.01^{\mathrm{b}}$ \\
\hline
\end{tabular}

Different letters $(a, b, c, d)$ in the same column are statistically different according to Tukey test carried out at $95 \%$ of confidence level

phenolic content and in antioxidant activity measured by the DPPH method. Moreover, for the $\mathrm{ABTS}^{+}$method, an increase of $50 \%$ in antioxidant activity was observed for samples fermented with $L$. reuteri. Juçara pulp is a highly pigmented presenting an intense purple colour. According to some studies, the differences between antioxidant activities determined by the above two methods are higher in pigmented foods than in non-pigmented foods (Samaniego Sanchez et al., 2007; Dudonné et al., 2009; Floegel et al., 2011). Besides, the $\mathrm{ABTS}^{+}$method presents a stronger correlation with total phenolic than the DPPH. assay (Chun et al., 2003; Floegel et al., 2011). These observations can explain the differences obtained in both methods observed in the present study, and a combination of both assays is therefore necessary to better elucidate the antioxidant activity in fermented juçara pulp, however according to Floegel et al., (2011), they are limited as they use non-physiological radicals. both methods are useful and popular in their application.

Although there were no results for antioxidant activity for juçara pulp in the literature, we found that the antioxidant activity was higher than that reported for cranberry, apple and grape juices commercially available in United States, which were $99.7 \pm 3.1 ; 22.8 \pm 2.2$ and $120.7 \pm 7.0(\mathrm{mg}$ vitamin $\mathrm{C}$ equivalent (VCE). $100^{-1} \mathrm{~g}$ ) respectively, for the ABTS method, and $67.2 \pm 6.2 ; 18.9 \pm 1.1$ and $102.6 \pm 1.5$ (mg VCE. $100^{-1} \mathrm{~g}$ ) for the DPPH method (Floegel et al., 2011).

The increased antioxidant activity may be hypothesised as occurring as follows. Firstly, during fermentation of the juçara pulp, the composition of bioactive compounds could be modified by LAB, since fermentation may induce structural breakdown of plant cell wall materials in the pulp through a decrease of $\mathrm{pH}$ that creates the condition for bound phenolic constituents to be released through enzymatic processes, leading to the liberation and/or synthesis of various bioactive compounds. Secondly, as discussed above, lactic acid bacteria can possess the enzyme $\beta$-glucosidase, which could modify the contents and structure of anthocyanins, changing from glycosides to the aglycon forms that result in an increased antioxidant activity (Dordevic et al., 2010, Hunaefl et al., 2013).

Some studies demonstrated that malvidin-3-glycoside could be converted to syringic and gallic acids (Fleschhut et al., 2006, Hidalgo et al., 2012), and ferulic and protocatechuic acids are mainly converted from cyanidin biotransformation (Kepler et al., 2005, Flores et al., 2015). Finally, the lower $\mathrm{pH}$ during fermentation process could have affected the extraction yield for phenolic content and antioxidant analysis, since the anthocyanins are relatively more stable at lowers $\mathrm{pH}$ values (Ruenroengklin et al., 2008).

Besides this, the increase in antioxidant capacity of fermented foods with probiotic bacteria may be influenced by factors such as microorganism species, $\mathrm{pH}$, temperature, water content, solvent, fermentation time, kind of food, and aerobic conditions (Hur et al., 2014). Additionally, studies suggest that the antioxidant activity may also be related to proteins present in the cell wall, or cell surface compounds such as exopolysaccharides (Kullisaar et al., 2002, Pan and Mei 2010, Li et al., 2012).

In relation to $L$ reuteri, Juarez et al. (2013) demonstrated that this strain had the highest capacity to reduce inflammatory and oxidative damages during endotoxin shock between others strains of Lactobacillus. This could be assigned to the capacity of its cell structure and their secreted molecules, which can explain the highest activity for $L$. reuteri in relation to L. plantarum found in the present study.

Although our study shows the influence of LAB fermentation in the juçara pulp for the first time, more detailed studies of the activities of relevant enzymes during fermentation are required to determine the exact mechanisms causing improvement of the nutritional effects (Dordevic et al., 2010). 


\section{Storage stability}

The juçara pulp fermented for 30 hours with $L$. reuteri (pH 5.7 and temperature at $32^{\circ} \mathrm{C}$ ), or L. plantarum ( $\mathrm{pH} 5.0$ and temperature at $25^{\circ} \mathrm{C}$ ), were maintained in glass vials at $4{ }^{\circ} \mathrm{C}$ for 28 days, and cell viability and antioxidant analysis were conducted every 7 days. During the 28 days of storage, the number of viable cells of $L$. reuteri and L. plantarum remained almost constant, maintaining numbers greater than $8.7 \pm 0.3 \log \mathrm{CFU} / \mathrm{mL}$ until the end of the storage period (Table 4). The cell viability during storage is dependent on factors such as oxygen levels within products, oxygen permeability in packaging, fermentation time and storage temperature, among others (Shah 2000, Pereira et al., 2014). In the present study, was used glass bottles, which presents a very low oxygen permeability, and a low storage temperature $\left(4^{\circ} \mathrm{C}\right)$, which could explain the maintenance of cell viability in the fermented juçara pulp. Additionally, according to Shah (2007), in order to produce beneficial effects, the probiotic bacteria must be available and viable at concentrations of at least $10^{6} \mathrm{CFU} / \mathrm{g}$, and our product presented higher numbers than this right through until the end of storage period assessed.

Pereira et al. (2011), while studying L. casei in cashew apple juice fermentation $\left(30^{\circ} \mathrm{C}\right.$ for 16 hours) with 42 days of refrigerated storage, reported an increased survival of the probiotic bacteria during the first 21 days of storage. By the $35^{\text {th }}$ day, there was a small reduction from $8.72 \log \mathrm{CFU} / \mathrm{mL}$ to $8.62 \log \mathrm{CFU} / \mathrm{mL}$ in viable cell numbers.

The antioxidant activity of fermented juçara pulp for either L. reuteri or L. plantarum during refrigerated storage showed a significant increase as determined by both radical sequestration methodologies (Table 4). As discussed above, this observation may be explained by the increase in the low molecular compounds and by the conversion of existing anthocyanins by fermentation into the aglycone forms (Hussain et al., 2016). Thus demonstrating that higher antioxidant potential can occur even at low temperatures $\left(4^{\circ} \mathrm{C}\right)$ (Otieno et al., 2005, Moraes Filho et al., 2014).
Additionally, Hornedo-Ortega et al. (2016) detected that the concentrations of the main anthocyanin compounds were preserved until 60 days of storage at low temperature $\left(4{ }^{\circ} \mathrm{C}\right)$. This trend was also found by Di Cagno et al. (2011) evaluating mashed fermented cherries with addition of lactic starter cultures, and resulted in an increase in antioxidant activity until the end of storage period. Therefore, the fermentation process could be considered an ideal method for preservation and improvement of nutritional properties for juçara pulp even during storage, thereby providing additional health benefits for its consumption by humans.

\section{CONCLUSION}

The maximal response conditions for the growth of each microorganism in juçara pulp was at $32{ }^{\circ} \mathrm{C}$ with a $\mathrm{pH}$ of 5.7 for $\mathrm{L}$. renteri and $25{ }^{\circ} \mathrm{C}$ with a $\mathrm{pH}$ of 5.0 for $L$. plantarum, and the proposed models presented a coefficient of determination of above $89 \%$ and can be used for predictive purposes. After $30 \mathrm{~h}$ of fermentation, the $L$. reuteri and $L$. plantarum showed counts above $8.6 \pm$ $0.2 \log \mathrm{CFU} / \mathrm{mL}$, with averages of $536.7 \mathrm{mg} \mathrm{GAE} / 100 \mathrm{~mL}$ of total phenolic compounds and an increase in antioxidant activity was also observed. During fermentation, L. reuteri consumed all glucose and fructose present in juçara pulp, and the appearance of rhamnose was observed, whereas L. plantarum consumed only glucose. After 28 days of refrigerated storage, the cell viability of probiotics remained at $8.7 \log \mathrm{CFU} / \mathrm{mL}$ for both microorganisms with an increase in the antioxidant activity. This study showed for the first time that pure juçara pulp can be used as a carrier of probiotic bacteria, resulting in large numbers of viable cells under optimised conditions, and can be kept viable during storage under refrigeration.

\section{ACKNOWLEDGEMENTS}

We would like to thank Conselho Nacional de Desenvolvimento Cientifico e Tecnológico (CNPq, Brazil) for financial support

Table 4: Viability of Lactobacillus plantarum and Lactobacillus reuteri (log CFU/mL), total phenolics and antioxidant activity of the fermented juçara pulp after storage for 28 days at $4{ }^{\circ} \mathrm{C}$.

\begin{tabular}{llcccc}
\hline Sample & & $\log \mathrm{CFU} / \mathrm{mL}$ & $\mathrm{DPPH} \cdot(\mu \mathrm{mol}$ Trolox $/ \mathrm{mL})$ & ABTS.$^{+}(\mu \mathrm{mol}$ Trolox/mL) & Total phenolic $(\mathrm{GAE} / 100 \mathrm{~mL})$ \\
\hline L. plantarum & 0 day & $8.89 \pm 0.05^{\mathrm{a}}$ & $148.3 \pm 12.21^{\mathrm{a}}$ & $58.3 \pm 3.53^{\mathrm{a}}$ & $546.1 \pm 5.35^{\mathrm{a}}$ \\
& 7 days & $8.81 \pm 0.02^{\mathrm{a}}$ & $158.5 \pm 3.53^{\mathrm{b}}$ & $63.9 \pm 2.14^{\mathrm{b}}$ & $631.7 \pm 5.67^{\mathrm{b}}$ \\
& 14 days & $8.73 \pm 0.06^{\mathrm{b}}$ & $160.5 \pm 3.76^{\mathrm{b}}$ & $74.4 \pm 2.36^{\mathrm{b}}$ & $705.1 \pm 9.37^{\mathrm{c}}$ \\
& 21 days & $8.71 \pm 0.13^{\mathrm{ab}}$ & $163.0 \pm 6.70^{\mathrm{bc}}$ & $76.5 \pm 1.50^{\mathrm{b}}$ & $717.4 \pm 4.01^{\mathrm{c}}$ \\
& 28 days & $8.73 \pm 0.05^{\mathrm{b}}$ & $170.7 \pm 6.88^{\mathrm{c}}$ & $81.8 \pm 1.41^{\mathrm{b}}$ & $635.3 \pm 1.33^{\mathrm{b}}$ \\
L. reuteri & 0 days & $8.92 \pm 0.05^{\mathrm{a}}$ & $161.8 \pm 5.63^{\mathrm{a}}$ & $55.8 \pm 2.40^{\mathrm{a}}$ & $531.1 \pm 3.73^{\mathrm{a}}$ \\
& 7 days & $8.85 \pm 0.03^{\mathrm{a}}$ & $167.6 \pm 1.32^{\mathrm{b}}$ & $71.3 \pm 1.26^{\mathrm{b}}$ & $706.4 \pm 2.77^{\mathrm{b}}$ \\
& 14 days & $8.80 \pm 0.10^{\mathrm{ab}}$ & $172.4 \pm 1.30^{\mathrm{b}}$ & $74.1 \pm 0.47^{\mathrm{b}}$ & $726.3 \pm 6.12^{\mathrm{c}}$ \\
& 21 days & $8.72 \pm 0.07^{\mathrm{b}}$ & $174.3 \pm 4.43^{\mathrm{bc}}$ & $75.3 \pm 2.36^{\mathrm{b}}$ & $674.9 \pm 5.83^{\mathrm{d}}$ \\
& 28 days & $8.71 \pm 0.05^{\mathrm{b}}$ & $179.1 \pm 2.65^{\mathrm{c}}$ & $76.6 \pm 3.53^{\mathrm{b}}$ & $659.0 \pm 10.1^{\mathrm{d}}$ \\
\hline
\end{tabular}

Different letters $(a, b, c, d)$ in the same column are statistically different according to Tukey test carried out at $95 \%$ of confidence level 
(Process number: 479623/2012-0) and a scholarship for K. B. G. We also like to thank Daniel Steidle from Bimini Farm for the juçara fruit used in the study.

\section{Authors' contributions}

K. B. Guergoletto designed the study, collected test data and drafted the manuscript. C. S. I. Saori participated in improving the experiment and S. Garcia designed the experiment and revised the manuscript.

\section{REFERENCES}

AOAC. 2005. Official Methods of Analysis of AOAC International. $18^{\text {th }}$ ed, AOAC International, Gaithersburg, MD.

Bligh, E. G. and W. J. Dyer. 1959. A rapid method of total lipid extraction and purification. Can. J. Biochem. Physiol. 37(8): 911-917.

Borges, G. S. C., F. G. K. Vieira, C. Copetti, L. V. Gonzaga, R. C. Zambiazi, J. M. Filho and R. Fett. 2011. Chemical characterization, bioactive compounds, and antioxidant capacity of Jussara (Euterpe edulis) fruit from the Atlantic Forest in southern Brazil. Food Res. Int. 44(7): 2128-2133.

Borges, G. S. C., I. V. Gonzaga, F. A. Jardini, J. M. Filho, M. Heller, G. Micke, A. C. O. Costa and R. Fett. 2013. Protective effect of Euterpe edulis M. on Vero cell culture and antioxidant evaluation based on phenolic composition using HPLC-ESI-MS/MS. Food Res. Int. 51: 363-369.

Brand-Williams, W., M. E. Cuvelier and C. Berset. 1995. Use of free radical method to evaluate antioxidant activity. Lebensom. Wiss. Technol. (LWT). 28(1): 25-30.

Cardoso, A. L., P. F. Di Pietro, F. G. K. Vieira, B. C. B. Boaventura, D. De Liz, G. S. C. Borges, R. Fett, F. Andrade and E. L. Silva. 2015. Acute consumption of juçara juice (Euterpe edulis) and antioxidant activity in healthy individuals. J. Funct. Foods. 17: 152-162.

Cai, Y., J. Liu, Y. Shi, L. Liang and S. Mou. 2005. Determination of several sugars in serum by high-performance anion-exchange chromatography with pulsed amperometric detection. J. Chromatogr. A. 1085(1): 98-103.

Chun, O. K., D.O. Kim, H. Y. Moon, H. G. Kang and C. Y. Lee. 2003. Contribution of individual polyphenolics to total antioxidant capacity of plums. J. Agric. Food Chem. 51(25): 7240-7245.

Costa, M. G. M., T. V. Fonteles, A. L. T. Jesus and S. Rodrigues. 2013. Sonicated pineapple juice as substrate for Lactobacillus casei cultivation for probiotic beverage development: Process optimisation and product stability. Food Chem. 139(1): 261-266.

De Brito, E. S., M. C. P. De Araújo, R. E. Alves, C. Carkeet, B. A. Clevidence and J. A. Noyotny. 2007. Anthocyanins present in selected tropical fruits: Acerola, Jambolão, Jussara, and Guajiru. J. Agric. Food Chem. 55(23): 9389-9394.

Di Cagno, R., R. F. Surico, G. Minervini, C. G. Rizello, R. Lovino, M. Servilli, A. Taticchi, S. Urbani and M. Gobbetti. 2011. Exploitation of sweet cherry (Prunus avium L.) puree added of stem infusion through fermentation by selected autochthonous lactic acid bacteria. Food Microbiol. 28(5): 900-909.

Ding, W. K. and Shah, N. P. 2008. Survival of free and microencapsulated probiotic bacteria in orange and apple juice. Int. Food Res. J. 15: 561-569.

Dordevic, T. M., S. S. Siler-Marinkovic and S. I. Dimitrijevic-Brankovic. 2010. Effect of fermentation on antioxidant properties of some cereals and pseudo cereals. Food Chem. 119(3): 957-963.

Dubois, M., K. A. Gilles, J. K. Hamilton, P. A. Rebers and F. Smith. 1956. Colorimetric method for determination of sugars and related substances. Anal. Chem. 28(3): 350-356.

Dudonné, S., X. Vitrac, P. Coutiere, M. Woillez and J. M. Merillon. 2009. Comparative study of antioxidant properties and total phenolic content of 30 plant extracts of industrial interest using DPPH, ABTS FRAP, SOD, ORAC assays. J. Agric. Food Chem. 57: 1768-1774.

Fang, Z. and B. Bhandari. 2011. Effect of spray drying and storage on the stability of bayberry polyphenols. Food Chem. 129(3): 1139-1147.

Felzenszwalb, I., M. R. C. Marques, J. L. Mazzei and C. A. F. Aiub. 2013. Toxicological evaluation of Euterpe edulis: A potential superfruit to be considered. Food Chem. Toxicol. 58: 536-544.

Fleschhut, J., F. Kratzer, G. Rechkemmer and S. E. Kulling. 2006 Stability and biotransformation of various dietary anthocyanins in vitro. Eur. J. Nutr. 45(1): 7-18.

Floegel, A., D.O. Kim, S.J. Chung, S. I. Koo and O. K. Chun. 2011. Comparison of ABTS/DPPH assays to measure antioxidant capacity in popular antioxidant-rich US food. J. Food Compost. Anal. 24: 1043-1048.

Flores, G., M. I. Casttillo, A. Costabile, A. Klee, K. B. Guergoletto and G. R. Gibson. 2015. In vitro fermentation of anthocyanins encapsulated with cyclodextrins: Release, metabolism and influence on gut microbiota growth. J. Funct. Foods. 16(1): 50-57.

Garbin, V. P. 2011. Análise da Atividade Antimicrobiana de Extratos de Frutas, Óleos de Sementes e Fungos Isolados da Palmeira de Juçara (Euterpe edulis Martius 1824). MSc Dissertation, Universidade Federal do Paraná, Brasil.

Guan, Y. G., P. Yu, S. J. Yu, X. B. Xu and X. L. Wu. 2012. Simultaneous analysis of reducing sugars and 5-hydroxymethyl-2-furaldehyde at low concentration by high performance anion exchange chromatography with electrochemical detector, compared with HPLC with refractive index detector. J. Dairy Sci. 95(11): 6379-6383.

Hayek, S., A. Shahbazi, M. Worku and S. A. Ibrahim. 2013. Enzymatic activity of Lactobacillus reuteri grown in a sweet potato based medium with the addition of metal ions. Springerplus. 2: 465-475.

Hidalgo, M., M. J. Oruna-Concha, S. Kolida, G. E. Walton, S. Kallithraka, J. P. E. Spencer and S. Pascual-Teresa. 2012 Metabolism of anthocyanins by human gut microflora and their influence on gut bacterial growth. J. Agric. Food Chem. 60(15): 3882-3890.

Hörmannsperger, G. and D. Haller. 2000. Molecular crosstalk of probiotic bacteria with the intestinal immune system: Clinical relevance in the context of inflammatory bowel disease. Int. J. Med. Microbiol. 300(1): 63-73.

Hornedo-Ortega, R., S. Krisa, M. C. García-Parrilla and T. Richard. 2016. Effects of gluconic and alcoholic fermentation on anthocyanin composition and antioxidant activity of beverages made from strawberry. Lebensom. Wiss. Technol. (LWT). 69: 382-389.

Hou, J. W., R. C. Yu and C. C. Chou. 2000. Changes in some components of soymilk during fermentation with bifidobacteria. Food Res. Int. 33(5): 393-397.

Hunaefl, D., D. N. Akumo and I. Smetanska. 2013. Effect of fermentation on antioxidant properties of red cabbages. Food Biotechnol. 27: 66-85.

Hur, S. J., S. Y. Lee, Y. C. Kim, I. Choi and G. B. Kim. 2014. Effect of fermentation on the antioxidant activity in plant-based foods. 
Food Chem. 160: 346-356.

Hussain, A., S. Bose, J. H. Wang, M. K. Yadav, G. B. Mahajan and H. Kim. 2016. Fermentation, a feasible strategy for enhancing bioactivity of herbal medicines. Food Res. Int. 81: 1-16.

Jaiswal, A. K., S. Gubta and N. Abu-Ghannam. 2012. Optimisation of lactic acid fermentation of York cabbage for the development of potential probiotic products. Int. J. Food Sci. Technol. 47: 1605-1612.

Jaiswal, A. K. and N. Abu-Ghannam. 2013. Kinetics studies for the preparation of probiotic cabbage juice: Impact on phytochemicals and bioactivity. Ind. Crops Prod. 50: 212-218.

Juarez, G. E., J. Villena, S. Salva, G. F. Valdez and A. V. Rodriguez. 2013. Lactobacillus reuteri CRL1101 beneficially modulate lipopolysaccharide-mediated inflammatory response in a mouse model of endotoxic shock. J. Funct. Foods. 5(4): 1761-1773.

Kepler, K. and H. U. Humpf. 2005. Metabolism of anthocyanins and their phenolic degradation products by the intestinal microflora. Bioorg. Med. Chem. 13(17): 5195-5205.

Kullisaar, T., M. Zilmer, M. Mikelsaar, T. Vihalemm, H. Annuk, C. Kairane and A. Kilk. 2002. Two antioxidative lactobacilli strains as promising probiotics. Int. J. Food Microbiol. 72: 215-224.

Li, S., Y. Zhao, L. Zhang, X. Zhang, L. Huang, D. Li, C. Niu, Z. Yang and Q. Wang. 2012. Antioxidant activity of Lactobacillus plantarum strains isolated from traditional Chinese fermented foods. Food Chem. 135(3): 1914-1919.

Moraes, F. M. L., S. S. Hirozawa, S. H. Prudêncio, E. I. Ida and S. Garcia. 2014. Petit suisse from black soybean: Bioactive compounds and antioxidant properties during development process. Int. J. Food Sci. Nutr. 65(4): 470-475.

Moreira, R. M., M. L. Martins, Jr. B. R. C. Leite, E. M. F. Martins, A. M. Ramos, M. Cristianini, A. N. R. Campos, P. C. Strigheta, V. R. O. Silva, J. W. Canuto, D. C. Oliveira and D. C. S. Pereira. 2017. Development of a juçara and Ubá mango juice mixture with added Lactobacillus rhamnosus GG processed by high pressure. LWT Food Sci. Technol. 77: 259-268.

Mousavi, Z. E., S. M. Mousavi, S. H. Razavi, Z. Emam-Djomeh and $\mathrm{H}$. Kiani. 2011. Fermentation of pomegranate juice by probiotic lactic acid bacteria. World J. Microbiol. Biotechnol. 27(1): 123-128.

Nurmi, E., L. Nuotto and C. Scheneitz. 1992. The competitive exclusion concept: Development and future. Int. J. Food Microbiol. 15: 237-240.

Otieno, D. O., J. F. Ashton and N. P. Shah. 2005. Stability of $\beta$-glucosidase activity produced by Bifidobacterium and Lactobacillus spp. in fermented soymilk during processing and storage. J. Food Sci. 70(4): M236-M241.

Pan, D. and X. Mei. 2010. Antioxidant activity of an exopolysaccharide purified from Lactococcus lactis subsp. lactis 12. Carbohyd. Polym. 80(3): 908-914.

Pereira, A. L. F., T. C. Maciel and S. Rodrigues. 2011. Probiotic beverage from cashew apple juice fermented with Lactobacillus casei. Food Res. Int. 44: 1276-1283.

Peres, C. M., C. Peres, A. Hernández-Mendoza and F. X. Malcata. 2012. Review on fermented plant materials as carriers and sources of potentially probiotic lactic acid bacteria: With an emphasis on table olives. Trends Food Sci. Tech. 26(1): 31-42.

Remus, D. M., M. Kleerebezem and P. A. Bron. 2011. An intimate têteà-tête - How probiotic lactobacilli communicate with the host. Eur. J. Pharmacol. 668: s33-s42.

Roginski, V. and E. A. Lissi. 2005. Review of methods to determine chain-breaking antioxidant activity in food. Food Chem. 92(2): 235-254.

Ruenroengklin, N., J. Zhong, X. Duan, B. Yang, J. Li and Y. Jiang. 2008. Effects of various temperatures and $\mathrm{pH}$ values on the extraction yield of phenolics from litchi fruit pericarp tissue and the antioxidant activity of extracted anthocyanins. Int. J. Mol. Sci. 9: $1333-1341$

Samaniego, S.C., G. A. M. Troncoso, M. C. Garcia-Parrilla, G. J. J. Quesada, G. S. H. López and M. M. C. López. 2007. Different radical scavenging tests in virgin olive oil and their relation to the total phenol content. Anal. Chim. Acta. 593: 103-107.

Sanchez-Gonzales, I., A. Joménez-Escrig and F. Saura-Calixto. 2005. In vitro antioxidant activity of coffee brewed using different procedures (Italian, Expresso and Filter). Food Chem. 90(1-2): 133-139.

Schulz, M., G. S. C. Borges, L. V. Gonzaga, S. K. T. Seraglio, I. S. Olivo, M. S. Azevedo, P. Nehring, J. S. Gois, T. S. Almeida, L. Vitali, D. A. Spudeit, G. A. Micke, D. L. G. Borges and R. Fett. 2015. Chemical composition, bioactive compounds and antioxidant capacity of juçara fruit (Euterpe edulis Martius) during ripening. Food Res. Int. 77(2): 125-131.

Shah, N. P. 2000. Probiotic bacteria: Selective enumeration and survival in dairy foods. J. Dairy Sci. 83(4): 894-907.

Shah, N. P. 2007. Functional cultures and health benefits. Int. Dairy J. 17(11): 1262-1277.

Spagna, G., R. N. Barbagallo, P. G. Pifferi, R. M. Blanco and J. M. Guisan. 2000. Stabilization of a $\beta$-glucosidase from Aspergillus niger by binding to an amine agarose gel. J. Mol. Catal. B: Enzym. 11: 63-69.

Silva, F. C. 2009. Manual de Análises Químicas de Solos, Plantas e Fertilizantes. Embrapa Informação Tecnológica, Brasília, Brasil.

Vieira, G. S., R. N. Cavalcanti, M. A. A. Meireles and M. D. Hubinger. 2013. Chemical and economic evaluation of natural antioxidant extracts obtained by ultrasound-assisted and agitated bed extraction from jussara pulp (Euterp edulis). J. Food Eng. 119(2): 196-204.

Yoon, K. Y., E. E. Woddams and Y. D. Hang. 2006. Production of probiotic cabbage juice by lactic acid bacteria. Bioresour. Technol. 97(12): 1427-1430.

Wang, Y. C., J. W. Hou, R. C. Yu and C. C. Chou. 2003. Sugars and acid contents in soymilk fermented with lactic acid bacteria alone or simultaneously with Bifidobacteria. Food Microbiol. 20(3): 333-338

Wyvill, L. 2012. UQ Probiotics Innovation Boosts of Milk and Juice. Available from: https://www.uniquest.com.au/news/uqprobiotics-innovation-boosts-health-benefits-of-milk-and-juice. [Last accessed on 2017 Sep 19]. 